\title{
Manu Prakash
}

\author{
Frugally built technology to study the ocean's microbes, and engineering for societal good.
}$$
\text { t's the "most stupendous snowfall," }
$$

a downward drift of "flake upon flake, layer upon layer" writes Rachel Carson in her 1951 book The Sea Around Us. This marine snow, says Stanford University biophysicist Manu Prakash, is made up of marine microorganisms, and also communities of them, that can traverse thousands of meters before they eventually die and drift to the seafloor. Measuring this marine snow and assessing these organisms' biology involves extensive observation that might include tracking microbes over a circadian cycle. These data can help with larger questions related to biogeochemical cycles and climate change. Enter the Prakash lab's scale-free vertical tracking microscope, also known as the hydrodynamic treadmill or the Gravity Machine.

The instrument can track floating microscopic marine organisms, imaging them as they behave and react to changes around them as they move from simulated sunlit shallows to pitch-black ocean depths. Instead of imaging on a horizontal plane like typical microscopes, this instrument has a vertically mounted circular fluidic chamber. This upright watery Ferris wheel acts as a rotating microbial treadmill. Microbes travel and yet stay in place, which makes the instrument "a virtual reality machine for single cells," says Prakash.

LED lights simulate sunlight and can be dimmed to mimic murky depths. Infrared imaging minimizes disturbance to the microbes, which experience vertical travels not unlike those they would undergo in the open ocean, including light, temperature and pressure changes. The objective lens is aimed at the 3 and 9 o' clock positions of the circular chamber; there is a camera and video is fed into a computer.

The lab is a diverse mix of biochemists, physicists, and electrical and mechanical engineers, and "we do a lot of field trips as a lab together," says Prakash. On a field trip to Madagascar they studied how the parasite that causes schistosomiasis detects people to infect in a freshwater lake. The lake might be 30 meters deep, but no microscope is 30 meters high. Prakash and graduate student Deepak Krishnamurthy brainstormed and sketched and came up with the idea of a circular chamber. The team did experiments with hula hoops and modeled objects

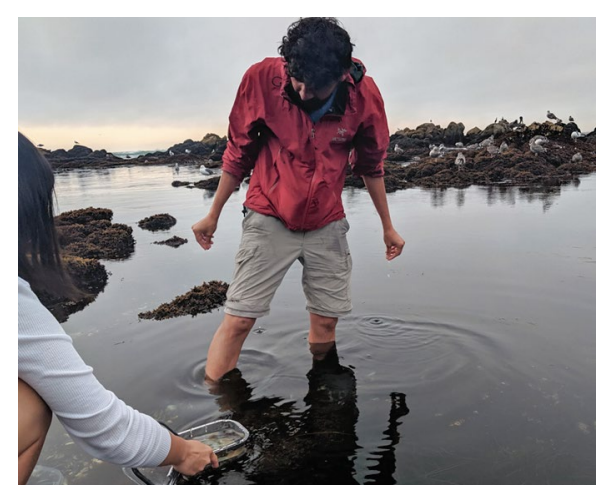

Manu Prakash. Credit: E. Underwood

traveling in rotating fluid to account for the viscous delay that influences the rotational flow of objects. "At the microscopic scale, the physics is completely non-intuitive," he says.

On a trip to Puerto Rico to field-test the new hydrodynamic treadmill, the team used it to observe a floating diatom. Suddenly, says Prakash, the diatom sank like a rock, then floated anew. "Organisms can change their density in a blink of an eye," he says of the observation, which changed how he thinks about diatoms. The team has taken the instrument onto seafaring research vessels, and one day, says Prakash, it might be used for in situ measurements as a buoy-mounted device.

The lab's technology is built frugally, with cost, performance and ease of use in mind, he says. The latest instrument is modular and built with open-source code and common parts. To scale the potential user base, the lab sets up communities of people who train others. "We think both about development and deployment," says Prakash. "It's been at the heart of every technology we work on."

Prakash's long list of inventions includes Handyfuge, a hand-powered centrifuge for SARS-CoV-2 testing in low-resource settings; PlanktonScope, a kit recreational sailors can use; Foldscope, a paper microscope that has reached one million people in around 140 countries; and Octopi, an automated microscope equipped with neural-network-based image analysis to rapidly find and count malaria parasites in blood samples. Octopi is the big brother of Foldscope and the treadmill is the "big, big brother," says Prakash.
The tools and methods of science determine who makes discoveries and "who gets to have a seat at the table," he says. Engineers often don't get technology into the hands of people in society, but "I can't look away," he says. Access to science is built into all of his projects.

Prakash grew up in India, and after his undergraduate training at Indian Institute of Technology, he completed his $\mathrm{PhD}$ at the Massachusetts Institute of Technology, followed by a fellowship at Harvard University. After that he joined the Stanford University faculty. His stack of awards includes a 'genius grant' from the MacArthur Foundation.

\section{We all make sure "what is true to our heart shows in our work."}

"We all have our own mechanisms to making sure what is true to our heart shows in our work," he says. "That's really a key, at least personally for me." When he finds the time, Prakash plays soccer, but mainly his fun is to explore the world using his inventions. "I will just dig in the dirt, take my Foldscope and observe for hours."

Manu Prakash is "one of the most imaginative scientists of his generation," says Alejandro Sánchez Alvarado, a Howard Hughes Medical Institute investigator and scientific director of Stowers Institute for Medical Research. "He exudes a contagious sense of curiosity, an attribute that never fails to elicit the memory of the fundamental reason why many of us chose to dedicate our lives to science: a need to understand the natural world around us," he says. Listening to Prakash speak formally and informally and reading his lab's papers always rekindles the joy we as scientists experience when we figure things out, he says. "Presently, Manu's work is curiosity-driven science in one of its purest forms."

Vivien Marx

Published online: 10 September 2020 https://doi.org/10.1038/s41592-020-0968-8

Reference

Krishnamurthy, D. et al. Scale-free vertical tracking microscopy. Nat. Methods https://doi.org/10.1038/ s41592-020-0924-7 (2020). 